\title{
How does monetary loss empathy modulate generosity in economic sharing behavior? An ERPs study
}

Authors and addresses:

Jia Jin ${ }^{1,2}$, Ailian Wang ${ }^{1,2}$, Jiaoyang Liu ${ }^{1,2}$, Jing Pan $^{1,2}$, Dong Lyu ${ }^{3 *}$

${ }^{1}$ Business School, Ningbo University, 818 Fenghua Road, Ningbo, 315211, China

${ }^{2}$ Academy of Neuroeconomics and Neuromanagement at Ningbo University, 818

Fenghua Road, Ningbo, 315211, China

${ }^{3}$ Business School, University of Nottingham Ningbo China, 199 Taikang East Road, Ningbo, 315100, China

*Corresponding author:

Dong Lyu

Business School, University of Nottingham Ningbo China

199 Taikang East Road, Ningbo 315100, China

E-mail: Dong.Lyu@nottingham.edu.cn 


\section{Abstract}

Previous studies have shown that generosity is driven by empathy and that both generosity in economic sharing behavior and monetary loss empathy decay as the social distance increases. However, it is still unclear whether this decay in economic sharing generosity can be influenced by the decay in monetary loss empathy. In the current study, we carried out two experiments to investigate this issue to deepen our understanding of the relationship between monetary loss empathy and generosity in economic sharing behavior. Our results show that in the observation group (observers watch their friend, and a stranger plays a gambling game), a negative correlation between log-transformed $\mathrm{k}$ value $(\ln (\mathrm{k}))$ and the distinction of $\mathrm{d}-\mathrm{FRN}$ (feedback-related negativity difference between gain and loss) between friends and strangers was observed. However, in the execution group (executors play a gambling game themselves and watch a stranger play the same gambling game), there was no significant correlation between $\ln (\mathrm{k})$ and the distinction of d-FRN between self and strangers. Current results indicate that the decayed generosity across different social distances in economic sharing behavior can be modulated by the decayed monetary loss empathy. The study adds weight to the relationship between decayed monetary loss empathy and decayed generosity in sharing economic behavior at the level of social distance and provides electrophysiological evidence.

Keywords: Monetary loss empathy; Generosity in economic sharing behavior; FRN; ERPs; Social discounting rate 


\section{Introduction}

Generosity is an important behavior enriching people's lives and is a basic cornerstone of human society (Strang \& Park, 2016). In social psychology, it is generally believed that generosity is motivated by empathy (Barraza \& Zak, 2009). Some studies have already investigated the relationship between generosity and empathy. For example, Griet (2011) found that empathic concern positively affects donation decisions, which means that empathy leads to generous behavior (Verhaert \& Van den Poel, 2011). Another study asked subjects to perform a classic dictator game and found that empathic feelings can be a key motivator for altruistic behavior in economic interactions (Klimecki, Mayer, Jusyte, Scheeff, \& Schönenberg, 2016). Moreover, a recent study has already focused on the relationship between empathy and generosity, which found that the effect of oxytocin on the decay rate of generosity behavior is modulated by trait empathy (Strang, et al., 2017).

Previous studies showed that people are not equally generous to everyone in economic sharing behaviors; they are more generous to those who they feel close to (e.g., mother) than those they do not feel that close to (e.g., a random stranger) (B. Jones \& Rachlin, 2006; B. A. Jones \& Rachlin, 2009; Ma, Pei, \& Jia, 2015). Jones and Rachlin (2006) defined a term called social discounting to describe the phenomenon in which generosity in economic sharing behaviors decreases as the social distance between individuals increases (B. Jones \& Rachlin, 2006). Many subsequent studies have confirmed the existence of this phenomenon and studied the factors that affect social discounts, such as culture (Strombach, et al., 2014), growth environment (Ma, et al., 
2015), and risk (Jin, Pei, \& Ma, 2017).

Moreover, several studies have also shown that individuals are prone to empathize with people they feel close to in both physical pain and monetary loss. For instance, Mina et al. (2011) studied individuals' empathy of physical pain and found that in-group members' suffering elicits enhanced empathic responses compared with out-group members' suffering (Cikara, Bruneau, \& Saxe, 2011). In addition, another study explored empathy in terms of monetary loss and found that individuals are more likely to show empathy to their friends than to strangers (Ma, et al., 2011).

However, no study has focused on the relationship between decayed generosity in economic sharing behavior and decayed monetary loss empathy, although both economic generosity and monetary loss empathy decay when social distance increases. Therefore, the current study aims to investigate the relationship between them. Specifically, we focus on whether and how an individual's empathy differs toward a friend's and a stranger's monetary loss and how this difference modulates the decay of economic generosity from close others to strangers. We supposed that there is a relationship between the decay of monetary loss empathy of friends vs. strangers and the decay of generosity in economic sharing behavior across social distances.

Previous studies have used the concept of social discounting to describe changes in economic sharing generosity across social distances (Jin, et al., 2017; Ma, et al., 2015; Strombach, et al., 2014). Social discounting means we tend to give more money to those we feel closer to than for those who are further from us in social distance. This concept was first suggested by Jones and Rachlin (2006), who also suppose that generosity 
decreases across social distance in a nonconstant, hyperbolic way (B. Jones \& Rachlin, 2006), as described by the equation below:

$$
\mathrm{v}=\frac{V}{1+\mathrm{k} D}
$$

where v symbolizes the discounted value, which is the willingness to be generous toward a person at a given social distance, and D represents the social distance. The parameter $V$ refers to the value of the undiscounted reward, which can be interpreted as the generosity level at close social distances. The parameter $\mathrm{k}$ refers to the discounting rate, i.e., the steepness and the asymmetry of the decline in generosity across social distance, which is used to estimate the decline of generosity across social distances (B. Jones \& Rachlin, 2006; Ma, et al., 2015; Strombach, et al., 2014). A large k indicates that generosity decreases rapidly, and a small $\mathrm{k}$ indicates that generosity decreases slowly across the social distance (Jin, et al., 2017; B. Jones \& Rachlin, 2006; Ma, et al., 2015; Strombach, et al., 2014). Furthermore, the area under the curve (AUC) of the shared money is closely associated with generosity, with a larger value indicating a higher level of generosity (Gong, Zhang, \& Fung, 2017; Margittai, et al., 2015; Strombach, et al., 2014). In the current study, we also intend to employ the social discounting task to investigate the decay of economic generosity. Therefore, we supposed that the phenomena of social discounting exist and fit the hyperbolic model well in the current study.

Regarding the empathy in monetary loss, several researchers have employed eventrelated potentials (ERPs) to study the related cognitive neural mechanisms (Fukushima \& Hiraki, 2006; Leng \& Zhou, 2010; Ma, et al., 2011). Their studies found that two 
ERP components, feedback-related negativity (FRN) and P300, are induced when feedback information from decision results of the gambling task is presented.

FRN is an ERP component distributed mainly over frontal-central regions of the scalp in the time window 200-300 ms after a feedback stimulus is presented (Gehring \& Willoughby, 2002; Holroyd \& Coles, 2002). FRN was first suggested by Gehring and Willoughby (2002) in a gambling task, which adopted a binary choice gambling task to study the brain response of monetary gain and loss. They found the FRN was sensitive to loss and gain differences in the outcome (Gehring \& Willoughby, 2002). Moreover, Fukushima and Hiraki (2009) extended such a gambling task to explore how subjects empathize with friends' or computers' monetary loss and found that, compared with observing computers, observing friends' loss and gain induced a greater FRN difference (d-FRN) (Fukushima \& Hiraki, 2009). Furthermore, another study conducted by $\mathrm{Ma}$ et al. showed that compared with observing those of strangers, observing friends' monetary loss and gain also induced larger FRN differences. The author explained it as the empathy difference between friends and strangers (Ma, et al., 2011). In the current study, we intend to employ a similar paradigm to study the monetary loss empathy according to Ma et al. Therefore, we also expected to observe FRN differences between friends' and strangers' monetary gain and loss.

The other ERP component is P300, which peaks around approximately 200-500 ms after stimulation, and its maximum amplitude is located at centro-parietal sites. P300 is proposed to be affected by attentional allocation and motivational/affective salience (Nieuwenhuis, Aston-Jones, \& Cohen, 2005). Previous studies found a valence effect 
of P300, with more positive amplitudes occurring for positive outcomes than for negative outcomes (Wu \& Zhou, 2009). Moreover, both Knyazev (2013) and Shen et al. (2013) observed a more pronounced P300 amplitude for the self than for others (Knyazev, 2013; Shen, Jin, \& Ma, 2013). Therefore, in the current study, we also supposed to find a P300 amplitude difference between self and others in the feedback of gambling tasks.

Then, as mentioned above, we intend to explore the relationship between the decayed generosity in economic sharing behavior and the decayed monetary loss empathy through the social discounting task and the gambling task for friends and strangers. The hypotheses are summarized as follows. First, similar to previous studies, the FRN amplitude differs between their own and others' gains and losses and further differs when observing friends' compared with strangers' performance. Second, generosity declines as a function of social distance and has a good fit with the hyperbolic model. Third, both economic generosity and monetary loss empathy decayed when social distance increased (B. Jones \& Rachlin, 2006; Ma, et al., 2011). We expect that the decay rate of generosity would have a positive effect on the different monetary loss empathic responses toward friends and strangers. This effect may be reflected in the negative correlation between the discounting rate and the differential d-FRN (negative polarity ERP component: large d-dFRN amplitude means small voltage value). Specifically, a larger d-dFRN amplitude can lead to a larger discounting rate (i.e., a faster decay in generosity). 


\section{Materials and Methods}

\subsection{Participants}

Sixty-eight graduate or undergraduate students (34 biological gender-matched pairs who were self-reported good friends; 18 female pairs; mean age $=21.67$ years, S.D. $=2.43$ ) were recruited from Ningbo University as participants. Another two students, one male and one female, who were strangers to all the paired friends, with similar age, were recruited to join the game as confederates. The stranger male participated with the male friend pairs, while the female stranger participated with the female friend pairs; i.e., there are three participants with the same gender in each experiment: two of them were a pair of friends, and the third was a stranger. The paired friend was randomly resigned to the observation or execution group. Due to their incomplete comprehension of the experiment, data from four subjects (two males) in the observation group were discarded, leaving 64 valid participants (30 observers and 34 executors) for final data analysis. All participants were healthy, native Chinese speakers who were right-handed, had normal or corrected to normal vision and did not have any history of neurological or mental diseases. All participants also provided written informed consent before the experiment started. The current experiment was approved by the internal review committee of the Academy of Neuroeconomics and Neuromanagement at Ningbo University. 


\subsection{Experimental design}

The experiment includes two stages. The first stage is a behavioral social discounting experiment that aims to explore the decay rate of economic generosity for each participant with a typical social discounting task. The second stage is a gambling task recording EEG that aims to investigate the same participants' different brain responses toward monetary gains and losses by a stranger and their friend, which may be explained as being induced by monetary loss empathy.

\subsubsection{Study 1: Behavioral social discounting task}

In this stage, we intend to test participants' decay of generosity in economic sharing behavior according to previous studies about social discounting (B. Jones \& Rachlin, 2006; B. A. Jones \& Rachlin, 2009; Strombach, et al., 2014; Takahashi, 2007, 2010). Similar to previous studies (Jin, et al., 2017; Ma, et al., 2015; Strombach, et al., 2014), the task begins with a self-representation task that asked subjects to use a 20-point scale to rate their perceived closeness to fourteen specific people in their social environment (mother, father, siblings, grandparent, family, relative, best friend, circle of friends, colleagues, neighbors, acquaintances, partners, child and strangers). If one of them did not exist in the real social context of the subject (for example, a participant has no child), they would skip the current trial. This task aims to give the subjects a concept of establishing a connection between the social distance of digital expression and the people with a corresponding social distance in the real environment.

The second step is the formal social discounting experiment. Each participant was 
asked to complete 63 separate binary choices that included seven social distances $\times$ nine monetary amounts for the selfish option. The participant was asked to imagine a real person who represented a specific social distance, and the participant had to choose between a selfish and a generous option. At the end of each trial, the screen would show the decision result. The procedure of one trial is shown in Fig 1.

As in the experiment by Jones and Rachlin, participants were asked to make the decision for people at the following seven distances: 1, 2, 5, 10, 20, 50, 100 (B. Jones \& Rachlin, 2006). Social distance was measured on a scale including 100 icons. The pink icon on the far left represented the participant. The yellow icon represented the recipient, who shares a fixed magnitude of money with the participant. If the yellow icon is next to the pink icon (social distance 1), this position means the person is part of the social environment to which the participant feels closest (e.g., their mother). If the yellow icon is on the far right of the scale (social distance 100), the person is at the farthest distance from the participant socially and is someone he/she did not care about but has no negative feelings toward.

In each trial, the participant had a choice between a selfish and a generous option at the given distance. The nine selfish options ranged from 130 to 290 yuan, with increments of 20 yuan. The generous option was a fixed amount of 130 yuan for the participant and the interaction partner (Jin, et al., 2017; Ma, et al., 2015; Strombach, et al., 2014; Tina, et al., 2015). 
Subsequent to the task, in the third step, participants were asked to fill out a questionnaire naming and describing their relationships to the people they used as interaction partners for each of the seven social distances. The major purpose of the questionnaire was to collect the demographic information and pay for the subject's rewards. At the end of the experiment, one trial within the experiment was randomly chosen by participants and received $5 \%$ of the real decision value as part of the participation fee. If the chosen decision was generous, both the participant and the other person involved in the randomly selected trial received 6.5 yuan. If a selfish option was selected, the participant received between 6.5 and 14.5 yuan, depending on the chosen trial. At the same time, the interaction partners would also receive 6.5 yuan by Alipay (Alipay is a form of online payment in China, similar to PayPal). Participants also had the option of donating the interaction partner's money to a charity instead. Information about this possibility was only given at the end of the experiment and, thus, could not have influenced subjects' choices. The experiment did not include deception and was performed in an incentive-compatible way, thus meeting the standards for economic research (Bonetti, 1998; Schram, 2005).

The experiment was presented using the E-prime 3.0 software package (psychology software tools). All trials were randomly presented.

\subsubsection{Study 2: EEG experiment of gambling task}

After the behavioral experiment, the following gambling task was performed. Each 
experimental group involved three subjects of the same biological gender, including two gender-matched friends and one same gender stranger to the paired friends. Before the EEG experiment, the stranger met the paired friend; they said hello to each other and were informed of the gambling task. During the experiment, the paired friends and stranger could not see each other; they sat separately in three adjacent opaque electrically shielded rooms, as shown in Fig 2a. At random, one of the friends (named the executor) and the stranger took turns in a gambling game, while the other friend was asked to just observe the friend and a stranger playing the game; we called this participant the observer. The screen was the same for all three participants, which means the loss or gain results could be seen by all of them. The friends' EEGs were recorded simultaneously, but the stranger's EEGs were not recorded. Thus, the brain response of the observation group was the difference between the gambling feedback results of strangers and friends, while the brain response of the executive group was the difference between the gambling feedback results of strangers and themselves. Before the formal experiment, we told the participants who were involved in the gambling task that their gains and losses, according to their performance in each round, would be added to or subtracted from their basic payment (30 yuan), and they were encouraged to earn as much as possible. In every round, the player's name would appear on the screen before the gambling game to let all three participants know who was playing the gambling game. We asked all the participants to pay attention to the selection and outcome feedback of the two confederates. 
The gambling task was adapted from Gehring and Willoughby's gambling task (WJ $\& A R, 2002)$. The stimuli were presented at the center of a computer screen at a distance of $100 \mathrm{~cm}$, with a visual angle of $8.69^{\circ} \times 6.52^{\circ}(15.2 \mathrm{~cm} \times 11.4 \mathrm{~cm}$, width $\times$ height $)$. As illustrated in Fig 2b, each trial began with the display of two blank cards for $500 \mathrm{~ms}$. Subsequently, two squares with thin white borders appeared horizontally on the background for 400 - $600 \mathrm{~ms}$ variably, with the two possible options of a 5 or a 25 betting card then being displayed to them. The player who was participating in that round was asked to make a selection from the two cards with a key press, pressing the number " 1 " on the keyboard for the left card or the number " 3 " for the right card. The results of the feedback were displayed by highlighting the chosen card with a red or blue color to indicate a gain or a loss, including the "+" and "-" symbols to increase the salience of the stimulus, which lasted 1 s. Then, the selected card would remain highlighted for 800 - $1200 \mathrm{~ms}$ (mean duration $1 \mathrm{~s}$ ). The red and blue color was counterbalanced across participants, and the placement of the 5 and 25 cards on the left or right was random. The feedback on gains and losses was randomly presented, both with the same probability. After finishing the experiment, the participant was informed of the final value of the outcome. Participants were informed that a " 5 " on a card means 0.5 yuan and " 25 " represents 2.5 yuan in their final reward. The executing player received between 25 and 35 yuan (mean $=30$ yuan), depending on their chosen value, and the observer received a fixed value of 30 yuan. 
The gambling task contained 240 trials, classified into 5 blocks of 48 trials, and each block included 2 rounds of 24 trials each. Each player completed one round every block. The order of the two participants in each block was pseudo-randomly arranged by the program. Practice trials were administered before the formal experiment.

\subsection{EEG data recording}

Electroencephalograms (EEGs) were recorded (bandpass $0.05-100 \mathrm{~Hz}$, sampling rate $1000 \mathrm{~Hz}$ ) using a Neuroscan Synamp2 Amplifier (curry8, Neurosoft Labs, Inc., Virginia, USA) with $\mathrm{Ag} / \mathrm{AgCl}$ electrodes placed at 64 scalp sites according to the extended international 10-20 system. An electrode between $\mathrm{PFz}$ and $\mathrm{Fz}$ on the forehead was connected as the ground, and the left mastoid was selected as an online reference. Vertical and horizontal electrooculograms (EOGs) were recorded by two pairs of electrodes, one pair placed above and below the left eye in parallel with the pupil and the other pair placed $10 \mathrm{~mm}$ from the lateral canthi. We started the gambling task only when the electrode impedances were maintained below $5 \mathrm{k} \Omega$.

EEG recordings were digitally filtered with a low-pass, $30 \mathrm{~Hz}$ filter (24 dB/octave). EOG artifacts were corrected using the method proposed by Semlitsch et al. (1986) (Semlitsch, Anderer, Schuster, \& Presslich, 1986). The signal was segmented to analyze the epoch from $200 \mathrm{~ms}$ before the onset of feedback to $800 \mathrm{~ms}$ after the onset, with the first $200 \mathrm{~ms}$ prestimulus used as a baseline. Trials containing amplifier clipping, bursts of electromyography activity, or peak-to-peak deflection exceeding $\pm 100 \mu \mathrm{V}$ were excluded. 
According to agency (2) $\times$ valence (2), the EEG epochs were averaged for 4 conditions (stranger loss, stranger gain, friend/self-loss, friend/self-gain) for each group of participants. Then, the difference wave was also generated by subtracting the ERPs elicited by the gain trials from the ERPs elicited by loss trials for each group of participants.

\subsection{Data analysis}

\subsubsection{Behavioral data analysis}

In the social discounting experiment, at each level of social distance, we obtained the cross point between a selfish and a generous option where there was no difference between the two choices, which was determined by titrating the selfish reward magnitude from 130 to 290 yuan. Logistic regression was used to determine the critical cross point at which the statistical probability of answering selfishly or generously is $50 \%$. According to previous studies about social discounting, if a person always makes a selfish or generous decision at a particular social distance level, the critical points were assumed to be 120 and 300 yuan, respectively (Jin, et al., 2017; Ma, et al., 2015; Strombach, et al., 2014). According to the experimental settings, we obtained a cross point at each of the seven chosen social distances for each participant. We calculated the amount of money forgone by the cross point minus 130 to compare the amount of money the participant would forgo with the generous and selfish options. A standard hyperbolic model [equation (1)] was fitted, in which we used the money forgone as the discounted value $\mathrm{v}$ and social distance to estimate the undiscounted value $\mathrm{V}$ and the 
discount rate $\mathrm{k}$ for each participant and group. The fitted curve of two groups is shown in Fig 3. To further quantify individual differences in social discounting, we also calculated the AUC of shared money for each participant and the two groups. Then, we normalized the AUC for each subject to standardized data and log-transformed k value $(\ln (\mathrm{k}))$ for the data analysis.

\subsubsection{EEG data analysis}

Based on visual observation and the guidelines proposed by Picton et al. (Picton, et al., 2000), we analyzed the mean amplitude of the FRN at the time window 140-190 ms after the onset of feedback. The mean amplitude of P300 was analyzed in both groups in the 280-460-ms time window after feedback onset. We selected nine electrodes in the frontal area $(\mathrm{F} 1, \mathrm{Fz}, \mathrm{F} 2, \mathrm{FC} 1, \mathrm{FCz}, \mathrm{FC} 2, \mathrm{C} 1, \mathrm{Cz}, \mathrm{C} 2)$ for the $\mathrm{FRN}$ and nine electrodes in the central-parietal area $(\mathrm{C} 1, \mathrm{Cz}, \mathrm{C} 2, \mathrm{CP} 1, \mathrm{CPz}, \mathrm{CP} 2, \mathrm{P} 1, \mathrm{Pz}, \mathrm{P} 2)$ for P300 in the statistical analysis. Within-subjects repeated-measures ANOVA for the FRN was performed with agency $($ friend/self and stranger $) \times$ valence $($ gain, loss $) \times$ electrodes $(\mathrm{F} 1$, Fz, F2, FC1, FCz, FC2, C1, Cz, C2) for each group. ANOVA for P300 was performed with agency $($ friend/self and stranger $) \times$ valence $($ gain, loss $) \times$ electrodes $(\mathrm{C} 1, \mathrm{Cz}, \mathrm{C} 2$, $\mathrm{CP} 1, \mathrm{CPz}, \mathrm{CP} 2, \mathrm{P} 1, \mathrm{Pz}, \mathrm{P} 2)$ for each group. Then, ANOVA for the d-FRN was also performed with agency (friend/self and stranger) $\times$ electrodes $(\mathrm{F} 1, \mathrm{Fz}, \mathrm{F} 2, \mathrm{FC} 1, \mathrm{FCz}$, FC2, C1, Cz, C2) for each group. The Greenhouse-Geisser correction was applied when the assumption of sphericity was violated (Greenhouse \& Geisser, 1959). If there was an interaction effect between factors, a simple effect analysis was conducted. Finally, a 
correlation analysis between the behavioral data and EEG data was performed.

\section{Results}

\subsection{Behavioral result: Social Discount Function}

A standard hyperbolic model was matched to the mean value of the amount forgone by each group, indicating a good fit for the observation group data $\left(X^{2}=8.7893\right.$, $\left.\mathrm{R}^{2}=0.9760\right)$ and the execution group data $\left(\mathrm{X}^{2}=8.7909, \mathrm{R}^{2}=0.9960\right)$, which is shown in Table 1 and Fig 3.

Table 1. Social Discount Parameters of the observation and execution groups

\begin{tabular}{llll}
\hline Model & Group & Mean fit & Fitted parameters \\
\hline Hyperbolic & Observation & $R^{2}=0.9760 ;$ & $k=0.0536 ;$ \\
model & & $X^{2}=8.7893$ & $V=155.4247 ;$ \\
& & $A U C=0.3832$ \\
\hline Hyperbolic & Execution & $R^{2}=0.9960 ;$ & $k=0.0450 ;$ \\
model & & $X^{2}=7.9179$ & $V=155.0278 ;$ \\
& & $A U C=0.4043$ \\
\hline
\end{tabular}

Figure 3 presents the mean amount forgone and the hyperbolic discount function fitted curve of the two groups. As summarized in Fig 3, the mean amount of forgone money was not different between the two groups at each social distance.

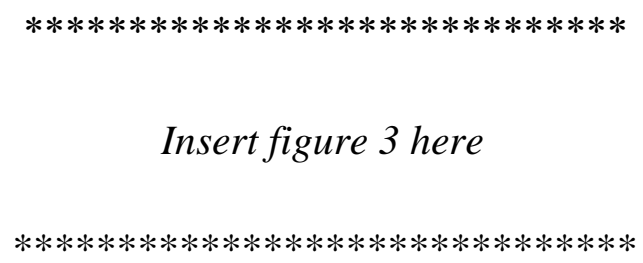

\subsection{EEG results}

\subsubsection{FRN results of the observation group}

We conducted a three-way 2 (agency) $\times 2$ (valence) $\times 9$ (electrodes) repeated- 
measures ANOVA of the mean FRN amplitudes of the observation group. There was no significant main effect of agency $\left[\mathrm{F}(1,29)=0.016, p=0.900, \eta_{\mathrm{p}}^{2}=0.001\right]$ and electrode $\left[F(8,232)=1.138, p=0.378, \eta_{p}^{2}=0.293\right]$, neither between agency and electrode $\left[\mathrm{F}(8,232)=0.502, p=0.841, \eta_{\mathrm{p}}^{2}=0.154\right]$ nor between valence and electrode $\left[\mathrm{F}(8,232)=2.047, p=0.088, \eta_{\mathrm{p}}^{2}=0.427\right]$, in the interaction effect; moreover, the interaction effect of the three factors of agency, valence and electrode was also not significant $\left[\mathrm{F}(8,232)=1.319, p=0.285, \eta_{\mathrm{p}}^{2}=0.324\right]$. However, the main effect of valence was significant $\left[\mathrm{F}(1,29)=8.454, p=0.007, \eta_{\mathrm{p}}^{2}=0.226\right]$, which means that the overall FRN amplitude was smaller in gain trials $(\mathrm{M}=1.265 \mu \mathrm{V}$, S.E. $=0.379)$ than in loss trials $(\mathrm{M}=0.415 \mu \mathrm{V}$, S.E. $=0.334$; the $\mathrm{FRN}$ has a negative polarity, so a small voltage means a larger amplitude). An interaction effect between agency and valence was also observed $\left[\mathrm{F}(1,29)=6.110, p=0.020, \eta_{\mathrm{p}}^{2}=0.174\right]$. Further simple effect analysis indicated that the difference between gains and losses was significant in the friend condition $\left[\mathrm{F}(1,29)=13.007, p=0.001, \eta_{\mathrm{p}}^{2}=0.31\right]$, which indicated that gain conditions $(\mathrm{M}=1.536 \mu \mathrm{V}$, S.E. $=0.413)$ elicited significantly smaller FRN amplitudes than loss conditions $(\mathrm{M}=0.166 \mu \mathrm{V}$, S.E. $=0.396)$. However, this difference was not significant in the stranger condition $\left[\mathrm{F}(1,29)=0.016, p=0.900, \eta_{\mathrm{p}}^{2}=0.001\right]$. In terms of the d-FRN, two-way 2 (agency) $\times 9$ (electrodes) repeated-measures ANOVA was conducted, which showed a significant main effect of agency $[\mathrm{F}(1,29)=6.110, p$ $\left.=0.020, \eta_{\mathrm{p}}^{2}=0.174\right]$, and the friend's loss-gain condition $(\mathrm{M}=-1.371 \mu \mathrm{V}, \mathrm{S} . \mathrm{E} .=0.380)$ evoked an obviously larger deflection than the stranger's loss-gain condition (M $=-0.329 \mu \mathrm{V}$, S.E. $=0.339)$, as presented in Fig 4. However, the main effect of electrode 
$\left[F(8,232)=2.047, p=0.088, \eta_{p}^{2}=0.427\right]$ and the interaction effect between agency and electrode $\left[\mathrm{F}(8,232)=1.319, p=0.285, \eta_{\mathrm{p}}^{2}=0.324\right]$ was not significant.

\section{Insert figure 4 here}

$* * * * * * * * * * * * * * * * * * * * * * * * * * * * * *$

\subsubsection{P300 results of the observation group}

Additionally, three-way 2 (agency) $\times 2$ (valence $) \times 9$ (electrodes) repeated-measures ANOVA for the P300 amplitudes revealed a significant main effect of valence $[\mathrm{F}(1,29)$ $\left.=5.493, p=0.026, \eta_{\mathrm{p}}^{2}=0.159\right]$ and electrode $\left[\mathrm{F}(8,232)=3.109, p=0.017, \eta_{\mathrm{p}}^{2}=0.531\right]$; gain conditions $(\mathrm{M}=7.613 \mu \mathrm{V}$, S.E. $=0.814)$ induced a larger $\mathrm{P} 300$ than loss conditions $(\mathrm{M}=6.865 \mu \mathrm{V}$, S.E. $=0.797)$. We also observed a significant interaction between valence and electrode $\left[F(8,232)=2.547, p=0.039, \eta^{2}{ }_{p}=0.481\right]$. However, the main effect of agency was not significant $\left[\mathrm{F}(1,29)=2.543, p=0.122, \eta_{\mathrm{p}}^{2}=0.081\right]$, neither between agency and electrode $\left[\mathrm{F}(8,232)=0.842, p=0.577, \eta^{2} \mathrm{p}=0.234\right]$ nor between agency and valence $\left[F(8,232)=0.003, p=0.954, \eta^{2}=0.000\right]$, in the interaction effect. The interaction effect of the three factors of agency, valence and electrode was also not significant $\left[\mathrm{F}(8,232)=1.022, p=0.449, \eta^{2} \mathrm{p}=0.271\right]$, as shown in Fig 5 .

$* * * * * * * * * * * * * * * * * * * * * * * * * * * * *$

Insert figure 5 here

$* * * * * * * * * * * * * * * * * * * * * * * * * * * * * *$

\subsubsection{FRN results of the execution group}

In the execution group, repeated-measures ANOVA for the FRN with three factors (agency, valence and electrode) revealed a main effect of agency $[\mathrm{F}(1,33)=14.082, p$ 
$\left.=0.001, \eta_{p}^{2}=0.299\right]$ and valence $\left[F(1,33)=15.025, p<0.001, \eta_{p}^{2}=0.313\right]$. The selfexecution condition $(\mathrm{M}=2.520 \mu \mathrm{V}$, S.E. $=0.383)$ elicited a smaller mean FRN amplitude than the stranger condition $(\mathrm{M}=1.357 \mu \mathrm{V}$, S.E. $=0.250)$, and gain conditions $(\mathrm{M}=2.512$ $\mu \mathrm{V}$, S.E. $=0.369)$ elicited significantly smaller FRN amplitudes than loss conditions (M $=1.365 \mu \mathrm{V}$, S.E. $=0.261)$. Additionally, the interaction effect between agency and valence was significant $\left[\mathrm{F}(1,33)=7.445, p=0.010, \eta_{\mathrm{p}}^{2}=0.184\right]$. Simple effect analysis revealed that the difference between gains and losses was significant in the selfexecution condition $\left[\mathrm{F}(1,33)=22.974, p<0.001, \eta_{\mathrm{p}}^{2}=0.410\right]$, which indicated that gain conditions $(\mathrm{M}=3.334 \mu \mathrm{V}$, S.E. $=0.477)$ elicited significantly smaller FRN amplitudes than loss conditions $(\mathrm{M}=1.706 \mu \mathrm{V}$, S.E. $=0.350)$. However, this effect was not significant in the stranger-observer condition $\left[\mathrm{F}(1,33)=3.617, p=0.066, \eta_{\mathrm{p}}^{2}=0.099\right]$. The electrode effect was not significant $\left[\mathrm{F}(8,264)=1.380, p=0.251, \eta_{\mathrm{p}}^{2}=0.298\right]$, neither between agency and electrode $\left[\mathrm{F}(8,264)=2.285, p=0.053, \eta_{\mathrm{p}}^{2}=0.413\right]$ nor between valence and electrode $\left[\mathrm{F}(8,264)=2.113, p=0.071, \eta_{\mathrm{p}}^{2}=0.394\right]$, in the interaction effect; moreover, the interaction effect of the three factors of agency, valence and electrode was also not significant $\left[\mathrm{F}(8,264)=0.279, p=0.967, \eta_{\mathrm{p}}^{2}=0.079\right]$. Furthermore, two-way (agency and electrode) repeated-measures ANOVA for the dFRN showed a significant main effect of agency $\left[\mathrm{F}(1,34)=7.445, p=0.010, \eta^{2}{ }_{\mathrm{p}}=0.184\right]$, in which the d-FRN mean amplitude elicited by self-execution $(\mathrm{M}=-1.628 \mu \mathrm{V}$, S.E. $=0.340)$ was significantly larger than that elicited by stranger-execution $(\mathrm{M}=-0.664$ $\mu \mathrm{V}$, S.E. $=0.349$ ), as shown in Fig 6 . The main effect of electrode reached marginal significance $\left[\mathrm{F}(8,264)=2.113, p=0.071, \eta_{\mathrm{p}}^{2}=0.394\right]$, whereas the interaction effect 
between agency and electrode was not observed $\left[\mathrm{F}(8,264)=0.279, p=0.967, \eta^{2} \mathrm{p}\right.$ $=0.079]$.

\section{Insert figure 6 here}

$* * * * * * * * * * * * * * * * * * * * * * * * * * * * * *$

\subsubsection{P300 results of the execution group}

P300 showed a significant main effect of agency $\left[\mathrm{F}(1,33)=218.557, p<0.000, \eta^{2} \mathrm{p}\right.$ $=0.869]$, valence $\left[\mathrm{F}(1,33)=6.278, p=0.017, \eta_{\mathrm{p}}^{2}=0.160\right]$ and electrode $[\mathrm{F}(8,264)=$ 8.719, $p<0.000, \eta_{\mathrm{p}}^{2}=0.728$ ], indicating that the mean P300 amplitude elicited by the self-execution condition $(\mathrm{M}=18.150 \mu \mathrm{V}$, S.E. $=0.930)$ was larger than that elicited by the stranger condition $(\mathrm{M}=7.58 \mu \mathrm{V}, \mathrm{S} . \mathrm{E} .=0.565)$. This result also means that the mean P300 amplitude elicited by the gain condition $(\mathrm{M}=13.316 \mu \mathrm{V}$, S.E. $=0.727)$ was larger than that elicited by the loss condition $(\mathrm{M}=12.423 \mu \mathrm{V}, \mathrm{S} . \mathrm{E} .=0.681)$. All the interaction effects were significant, namely, agency and valence $\left[\mathrm{F}(8,264)=13.096, p=0.001, \eta^{2} \mathrm{p}\right.$ $=0.284]$, agency and electrode $\left[\mathrm{F}(8,264)=5.6132, p<0.000, \eta_{\mathrm{p}}^{2}=0.633\right]$, and valence and electrode $\left[F(8,264)=2.904, p=0.019, \eta^{2}{ }_{p}=0.472\right]$. Simple effect analysis revealed that the difference between gains and losses was significant in the self-execution condition $\left[\mathrm{F}(1,33)=12.151, p=0.001, \eta_{\mathrm{p}}^{2}=0.269\right]$, which indicated that the gain condition $(\mathrm{M}=18.987 \mu \mathrm{V}$, S.E. $=1.003)$ elicited significantly larger P300 amplitudes than the loss condition $(\mathrm{M}=17.314 \mu \mathrm{V}$, S.E. $=0.916)$ in the self-execution condition. However, this effect was not significant in the stranger-execution condition $[\mathrm{F}(1,33)$ $\left.=0.111, p=0.741, \eta_{p}^{2}=0.003\right]$. Furthermore, the difference between self-execution and stranger-execution was also significant in both the gain condition $[\mathrm{F}(1,33)=181.328$, 
$\left.p<0.001, \eta^{2}{ }_{p}=0.846\right]$ and loss condition $\left[\mathrm{F}(1,33)=236.720, p<0.001, \eta^{2}=0.878\right]$, which indicated that the self-execution condition $\left(\mathrm{M}_{\text {gain }}=18.987 \mu \mathrm{V}, \mathrm{S} . \mathrm{E}\right.$.gain $=1.003$; $\left.\mathrm{M}_{\mathrm{loss}}=17.314 \mu \mathrm{V}, \mathrm{S} . \mathrm{E} \cdot \mathrm{loss}=0.916\right)$ elicited significantly larger P300 amplitudes than the stranger-execution condition $\left(\mathrm{M}_{\text {gain }}=7.645 \mu \mathrm{V}\right.$, S.E.gain $=0.638 ; \mathrm{M}_{\text {loss }}=7.531 \mu \mathrm{V}$, S.E.loss $=0.538)$ in the gain/loss condition. The interaction effect of the three factors of agency, valence and electrode was also not significant $\left[\mathrm{F}(8,264)=2.065, p=0.078, \eta^{2} \mathrm{p}=0.388\right]$.

$* * * * * * * * * * * * * * * * * * * * * * * * * * * * *$

$* * * * * * * * * * * * * * * * * * * * * * * * * * * * * *$

\subsection{Correlation analysis}

The social discounting rate $\mathrm{k}$ is not normally distributed (Kolmogorov-Smirnov's D $(64)=0.274, p<0.000)$; therefore, we log-transformed the $\mathrm{k}$ value into $\ln (\mathrm{k})$. The $\ln (\mathrm{k})$ test indicated a normal distribution ( $\mathrm{D}(64)=0.066, p=0.200)$. Then, we conducted a Spearman correlation analysis between behavioral data (ln (k), V and AUC) and EEG data (d-dFRN, d-dP300) in both the observation group and execution group. In the observation group, there was a significant negative correlation between $\ln (\mathrm{k})$ and the difference between the d-FRN difference of friends and strangers, while AUC was positively correlated with d-FRN difference (see Fig 8 for scatter plots), except for the intercept parameter V. There was also no significant correlation between behavioral data $(\ln (\mathrm{k}), \mathrm{V}$ and $\mathrm{AUC})$ and the d-P300 difference. Moreover, in the execution group, when participants were involved in the gambling game, there was no significant 
correlation effect between behavioral data $(\ln (k), V$ and AUC) and EEG data (d-FRN difference/ d-P300 difference between self and stranger), as shown in Table 2.

Table 2. Correlation results. The correlation results between the log-transformed discount rate value $(\ln (\mathrm{k})) / \mathrm{V} / \mathrm{AUC}$ and d-dFRN/ d-dP300 of three channel amplitudes for the two groups.

\begin{tabular}{|c|c|c|c|c|c|c|}
\hline & $\begin{array}{c}\text { d-dFRN } \\
(\mathrm{Fz})\end{array}$ & $\begin{array}{c}\text { d-dFRN } \\
(\mathrm{FCz})\end{array}$ & $\begin{array}{c}\mathrm{d}-\mathrm{dFRN} \\
(\mathrm{Cz})\end{array}$ & $\begin{array}{c}\mathrm{d}-\mathrm{dP} 300 \\
(\mathrm{CZ})\end{array}$ & $\begin{array}{c}\text { d-dP300 } \\
\text { (CPZ) }\end{array}$ & $\begin{array}{c}\text { d-dP300 } \\
(\text { PZ) }\end{array}$ \\
\hline $\begin{array}{l}\text { Observation } \\
\text { Group }(\ln (\mathrm{k}))\end{array}$ & $\begin{array}{c}r=-0.423 * \\
p=0.020\end{array}$ & $\begin{array}{c}r=-0.456^{*} \\
p=0.011\end{array}$ & $\begin{array}{c}r=-0.434 * \\
p=0.017\end{array}$ & $\begin{array}{l}r=-0.091 \\
p=0.631\end{array}$ & $\begin{array}{l}r=-0.099 \\
p=0.604\end{array}$ & $\begin{array}{l}r=-0.101 \\
p=0.594\end{array}$ \\
\hline $\begin{array}{c}\text { Observation } \\
\text { Group(V) }\end{array}$ & $\begin{array}{l}r=0.348 \\
p=0.059\end{array}$ & $\begin{array}{l}r=0.275 \\
p=0.142\end{array}$ & $\begin{array}{l}r=0.170 \\
p=0.369\end{array}$ & $\begin{array}{l}r=0.291 \\
p=0.119\end{array}$ & $\begin{array}{l}r=0.388 \\
p=0.034\end{array}$ & $\begin{aligned} r & =0.255 \\
p & =0.174\end{aligned}$ \\
\hline $\begin{array}{l}\text { Observation } \\
\text { Group(AUC) }\end{array}$ & $\begin{array}{l}r=0.382^{*} \\
p=0.037\end{array}$ & $\begin{array}{l}r=0.409 * \\
p=0.025\end{array}$ & $\begin{array}{l}r=0.382 * \\
p=0.037\end{array}$ & $\begin{array}{l}r=0.044 \\
p=0.817\end{array}$ & $\begin{aligned} r & =0.137 \\
p & =0.470\end{aligned}$ & $\begin{aligned} r & =0.127 \\
p & =0.505\end{aligned}$ \\
\hline $\begin{array}{c}\text { Execution } \\
\text { Group }(\ln (\mathrm{k}))\end{array}$ & $\begin{array}{l}r=0.190 \\
p=0.282\end{array}$ & $\begin{array}{l}r=0.187 \\
p=0.291\end{array}$ & $\begin{array}{l}r=0.096 \\
p=0.589\end{array}$ & $\begin{aligned} r & =0.167 \\
p & =0.346\end{aligned}$ & $\begin{array}{l}r=0.268 \\
p=0.126\end{array}$ & $\begin{array}{l}r=0.281 \\
p=0.107\end{array}$ \\
\hline $\begin{array}{l}\text { Execution } \\
\text { Group(V) }\end{array}$ & $\begin{array}{l}r=0.181 \\
p=0.306\end{array}$ & $\begin{array}{l}r=0.136 \\
p=0.445\end{array}$ & $\begin{aligned} r & =0.139 \\
p & =0.433\end{aligned}$ & $\begin{aligned} r & =0.008 \\
p & =0.965\end{aligned}$ & $\begin{aligned} r & =0.086 \\
p & =0.629\end{aligned}$ & $\begin{array}{l}r=0.121 \\
p=0.496\end{array}$ \\
\hline $\begin{array}{c}\text { Execution } \\
\text { Group(AUC) }\end{array}$ & $\begin{array}{l}r=-0.107 \\
p=0.545\end{array}$ & $\begin{array}{l}r=-0.135 \\
p=0.448\end{array}$ & $\begin{array}{c}r=-0.078 \\
p=0.661\end{array}$ & $\begin{array}{l}r=-0.044 \\
p=0.807\end{array}$ & $\begin{array}{l}r=-0.114 \\
p=0.520\end{array}$ & $\begin{array}{l}r=-0.143 \\
p=0.420\end{array}$ \\
\hline
\end{tabular}

$* * * * * * * * * * * * * * * * * * * * * * * * * * * * *$

Insert figure 8 here

$* * * * * * * * * * * * * * * * * * * * * * * * * * * * * *$

\section{Discussion}

Our study provides insight into whether the decayed monetary loss empathy affects the decayed generosity in economic sharing behavior. Behaviorally, the social discounting results support the findings of previous studies (Batson, Lishner, \& Stocks, 2015; Decety \& Jackson, 2004; B. Jones \& Rachlin, 2006; Ma, et al., 2011); i.e., the 
money forgone to others with different social distances can be fitted by a standard hyperbolic function for both observers and executors. Individuals tend to be more generous in economic sharing toward interaction recipients who are closer to them, and a larger social discounting rate reflects a faster decay rate of economic generosity between the different social distances.

At the brain level, we found a significant FRN difference (d-FRN) for friends' gains and losses but no obvious FRN difference for strangers' gains and losses in the observation group. In the execution group, self-executed gains and losses also elicited a significantly larger FRN difference, while strangers' gains and losses did not. These results were similar to those reported in Fukushima and Hiraki (2009) and Ma et al. (2011). For the execution group participants, it is easy to understand that they were more concerned about their own losses and gains than those of strangers in the economic task. With regard to their own economic benefits, people are always more concerned about themselves than friends or strangers in the gambling task, and selfparticipation induces social dominance seeking and weakens attention toward strangers (Rustichini, 2008). However, for the observers, there is no economic benefit for themselves; the d-FRN difference between friends and strangers revealed that they are more concerned about their friends' economic gains and losses compared with that of strangers. Previous studies explained that participants showed more empathy to their friends than strangers (Ma, et al., 2011).

Moreover, observation group participants showed no P300 difference between friend's and stranger's gains. However, in the execution group, the P300 component 
presented an obvious difference in the self's gains/losses and strangers' gains/losses, which is a similar result to that found in a previous study showing that people are more concerned about themselves than others in the gambling task (Ma, et al., 2011). The results showed that although FRN and P300 always appeared together at the feedback stage, these two components play different roles. As we stated in the introduction part, P300 is a component associated with attentional allocation and motivational/affective salience (Nieuwenhuis, et al., 2005). Our current results of P300 may be explained as the self's gambling outcome attracting more attention and having more motivational/affective salience than strangers' gambling outcome. However, this effect did not exist between friends' and strangers' gambling outcomes. This result is also consistent with previous studies, which suggested that P300 is associated with the difference between self and others (Leng \& Zhou, 2010; Ma, et al., 2011).

Furthermore, we investigated the relationship between the decay of generosity in economic sharing behavior and different levels of monetary loss empathy toward friends and strangers. The correlation result of the observation group reveals that there is a significant negative correlation between d-dFRN (differential d-FRN between friends and strangers) and the $\ln (\mathrm{k})$ (log-transformed $\mathrm{k}$ value) and a positive correlation between d-dFRN and AUC, but there is no significant correlation between $\ln (\mathrm{k}) / \mathrm{AUC}$ and d-dP300 amplitudes. Since the FRN is an ERP component with a negative polarity, a small voltage value indicates a large d-FRN amplitude; thus, the negative correlation means that a larger d-FRN amplitude difference can lead to a larger $\ln (\mathrm{k})$, and the positive correlation means that a larger d-FRN amplitude difference can lead to a 
smaller AUC. Previous studies have demonstrated that the FRN difference in observing friends vs. strangers play a risky gamble can be explained as different monetary loss empathy for friends and strangers (He, Sun, Shi, Zhang, \& Hu, 2018; Ma, et al., 2011). The larger $\ln (\mathrm{k})$ indicates a rapid decline in generosity, while a larger AUC indicates a higher level of generosity. Therefore, we supposed that the current result in the observation group can be explained as the economic generosity decay for different social distances being regulated by the decayed monetary loss empathy in economic tasks. However, in the execution group, the d-FRN difference had no significant relationship with $\ln (\mathrm{k})$. We considered that this was because the d-FRN difference between the observation and execution groups occurs for different reasons. According to previous studies, in the observation group, the d-FRN difference may relate to participants' different levels of empathy toward friends and strangers, while in the execution group, this difference may relate to the endogenous desire for dominance seeking, which may lead the participants to treat the self and others differently (Ma, et al., 2011; Rustichini, 2008). This idea suggests that the decayed economic generosity may be modulated by the decayed empathy rather than by a desire of dominance seeking in the economic environment.

The current study is the first to reveal the relationship between the decayed generosity in economic sharing behavior and the decayed monetary loss empathy with social distance increases. There are several implications of our findings. First, previous studies have suggested that empathy is intrinsic evidence of generous behavior (Klimecki, et al., 2016; Verhaert \& Van den Poel, 2011); the current study adds weight 
to the relationship between monetary loss empathy and generosity in economic sharing behavior at the level of social distance and provides electrophysiological evidence, which will help us better understand the relationship between them. Second, the social discounting theory addresses the decay of economic generosity across social distance (Jin, et al., 2017; B. Jones \& Rachlin, 2006; Ma, et al., 2015); furthermore, our findings indicated that decayed monetary loss empathy regulates this decay process. These results have noteworthy theoretical significance for recent advancements in social discounting. Third, several studies have confirmed that empathy affects an individual's generous behavior (Barraza \& Zak, 2009; Klimecki, et al., 2016), but the intrinsic relationship is not clear. Our research combining the social discounting paradigm with the gambling task while recording EEG showed that the decay of economic generosity across different social distances is modulated by different levels of monetary loss empathy toward friends and strangers. This interdisciplinary study offers a unique opportunity to understand the inner links between monetary loss empathy and an individual's generosity in economic sharing behavior.

In summary, the present study used behavioral experiments and ERPs to explore how an individual's decay of monetary loss empathy modulates the decay of generosity in economic sharing behavior. Our results suggest that participants' economic generosity and monetary loss empathy are regulated by social distance and have a significant negative correlation. There are several implications of the current findings. Nevertheless, we note here that this differentiation was an interesting finding that should be pursued in future research to further elucidate the mechanism of generosity. 
However, there are also some limitations of the current study. First, the current study did not measure the behavioral data of empathy but only focused on brain responses toward friends' and strangers' gains and losses in a gambling task. Although previous studies also did not measure behavioral data and supposed that FRN is associated with monetary loss empathy, FRN as a biomarker of empathy has not been proven yet. Therefore, it will helpful for us to build the relationship between monetary loss empathy and generosity in economic sharing behavior if we measure the behavioral data of empathy. Second, the friends paired with the same biological sex were asked to conduct the gambling task, while the psychological gender was not measured in this study. This is because we considered that Chinese culture and social norms may affect the authenticity of gender self-reporting. However, it will be better if we choose participants with the same psychological and biological gender in the task. We will take this into consideration in our future study. Third, the sample size for the correlation analysis was relatively small. The final data analyses included only 30 valid participants in the observation group and 34 valid participants in the execution group. A greater sample size may increase the robustness of the current results, which would further verify the current basic findings.

\section{Acknowledgments}

This work was supported by grant 71942002 and 71603139 from the National Natural

Science Foundation of China, was supported by project of leading academics of Social Sciences of Ningbo and sponsored by K.C. Wong Magna Fund in Ningbo University. 
Jia Jin was supported by project of leading researchers of Social Science of Ningbo. The funders had no role in study design; in the collection, analysis and interpretation of data; in the writing of the report; and in the decision to submit the article for publication.

\section{Conflicts of interest}

There are no conflicts of interest. 


\section{References}

Barraza, J., \& Zak, P. (2009). Empathy toward strangers triggers oxytocin release and subsequent generosity. Annals of the New York Academy of Sciences, 1167, 182-189.

Batson, C. D., Lishner, D. A., \& Stocks, E. L. (2015). 13 The Empathy-Altruism Hypothesis. The Oxford Handbook of Prosocial Behavior, 259-268.

Bonetti, S. (1998). Experimental economics and deception. Journal of Economic Psychology, 19, 377395.

Cikara, M., Bruneau, E. G., \& Saxe, R. R. (2011). Us and them: Intergroup failures of empathy. Current Directions in Psychological Science, 20, 149-153.

Decety, J., \& Jackson, P. L. (2004). The functional architecture of human empathy. Behavioral and cognitive neuroscience reviews, 3, 71-100.

Fukushima, H., \& Hiraki, K. (2006). Perceiving an opponent's loss: gender-related differences in the medial-frontal negativity. Social Cognitive and Affective Neuroscience, 1, 149-157.

Fukushima, H., \& Hiraki, K. (2009). Whose loss is it? Human electrophysiological correlates of non-self reward processing. Social neuroscience, 4, 261-275.

Gehring, W. J., \& Willoughby, A. R. (2002). The medial frontal cortex and the rapid processing of monetary gains and losses. Science, 295, 2279-2282.

Gong, X., Zhang, F., \& Fung, H. H. (2017). Are older adults more willing to donate? The roles of donation form and social relationship. The Journals of Gerontology: Series B, 74, 440-448.

Greenhouse, S., \& Geisser, S. (1959). On Methods in the Analysis of Profile Data Psychometrika 24: 95112. View Article PubMed/NCBI Google Scholar.

He, Q., Sun, Q., Shi, Z., Zhang, X., \& Hu, F. (2018). Effect of social distance on outcome evaluation in self-other decision-making: evidence from event-related potentials. Neuroreport, 29, 14991503.

Holroyd, C. B., \& Coles, M. G. (2002). The neural basis of human error processing: reinforcement learning, dopamine, and the error-related negativity. Psychological review, 109, 679.

Jin, J., Pei, G., \& Ma, Q. (2017). Social Discounting under Risk. Frontiers in Psychology, 8.

Jones, B., \& Rachlin, H. (2006). Social discounting. Psychological science, 17, 283-286.

Jones, B. A., \& Rachlin, H. (2009). Delay, probability, and social discounting in a public goods game. Journal of the experimental analysis of behavior, 91, 61-73.

Klimecki, O. M., Mayer, S. V., Jusyte, A., Scheeff, J., \& Schönenberg, M. (2016). Empathy promotes altruistic behavior in economic interactions. Scientific reports, 6, 31961.

Knyazev, G. (2013). EEG correlates of self-referential processing. Frontiers in human neuroscience, 7, 264.

Leng, Y., \& Zhou, X. (2010). Modulation of the brain activity in outcome evaluation by interpersonal relationship: an ERP study. Neuropsychologia, 48, 448-455.

Ma, Q., Pei, G., \& Jia, J. (2015). What Makes You Generous? The Influence of Rural and Urban Rearing on Social Discounting in China. Plos One, 10, e0133078.

Ma, Q., Shen, Q., Xu, Q., Li, D., Shu, L., \& Weber, B. (2011). Empathic responses to others' gains and losses: an electrophysiological investigation. Neuroimage, 54, 2472-2480.

Margittai, Z., Strombach, T., Van Wingerden, M., Joels, M., Schwabe, L., \& Kalenscher, T. (2015). A friend in need: time-dependent effects of stress on social discounting in men. Hormones and Behavior, 73, 75-82. 
Nieuwenhuis, S., Aston-Jones, G., \& Cohen, J. D. (2005). Decision making, the P3, and the locus coeruleus--norepinephrine system. Psychological bulletin, 131, 510.

Picton, T., Bentin, S., Berg, P., Donchin, E., Hillyard, S., Johnson, R., Miller, G., Ritter, W., Ruchkin, D., \& Rugg, M. (2000). Guidelines for using human event-related potentials to study cognition: recording standards and publication criteria. Psychophysiology, 37, 127-152.

Rustichini, A. (2008). Dominance and Competition. Journal of the European Economic Association, 6, 647-656.

Schram, A. (2005). Artificiality: The tension between internal and external validity in economic experiments. Journal of Economic Methodology, 12, 225-237.

Semlitsch, H. V., Anderer, P., Schuster, P., \& Presslich, O. (1986). A solution for reliable and valid reduction of ocular artifacts, applied to the P300 ERP. Psychophysiology, 23, 695-703.

Shen, Q., Jin, J., \& Ma, Q. (2013). The sweet side of inequality: how advantageous status modulates empathic response to others' gains and losses. Behavioural brain research, 256, 609-617.

Strang, S., Gerhardt, H., Marsh, N., Artigas, S. O., Hu, Y., Hurlemann, R., \& Park, S. Q. (2017). A matter of distance-The effect of oxytocin on social discounting is empathy-dependent. Psychoneuroendocrinology, 78, 229-232.

Strang, S., \& Park, S. Q. (2016). Human cooperation and its underlying mechanisms. In Social Behavior from Rodents to Humans (pp. 223-239): Springer.

Strombach, T., Jin, J., Weber, B., Kenning, P., Shen, Q., Ma, Q., \& Kalenscher, T. (2014). Charity begins at home: Cultural differences in social discounting and generosity. Journal of Behavioral Decision Making, 27, 235-245.

Takahashi, T. (2007). Non-reciprocal altruism may be attributable to hyperbolicity in social discounting function. Medical hypotheses, 68, 184-187.

Takahashi, T. (2010). A social discounting model based on Tsallis' statistics. Physica A: Statistical Mechanics and its Applications, 389, 3600-3603.

Tina, S., Bernd, W., Zsofia, H., Peter, K., Karipidis, I. I., Tobler, P. N., \& Tobias, K. (2015). Social discounting involves modulation of neural value signals by temporoparietal junction. Proceedings of the National Academy of Sciences of the United States of America, 112, 16191624.

Verhaert, G. A., \& Van den Poel, D. (2011). Empathy as added value in predicting donation behavior. Journal of Business Research, 64, 1288-1295.

WJ, G., \& AR, W. (2002). The medial frontal cortex and the rapid processing of monetary gains and losses. Science, 295, 2279-2282.

Wu, Y., \& Zhou, X. (2009). The P300 and reward valence, magnitude, and expectancy in outcome evaluation. Brain Research, 1286, 114-122. 


\section{Figure legends}

Fig 1. (a) Example of the self-representation task. (b) Example of the social discounting experiment. In each trial, there are two screens. First, the social distance information and a generous and selfish reward offer were presented. Second, the decision result was shown.

(a)

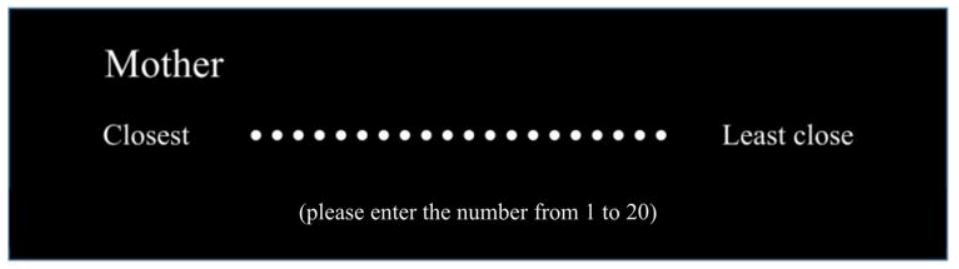

(b)

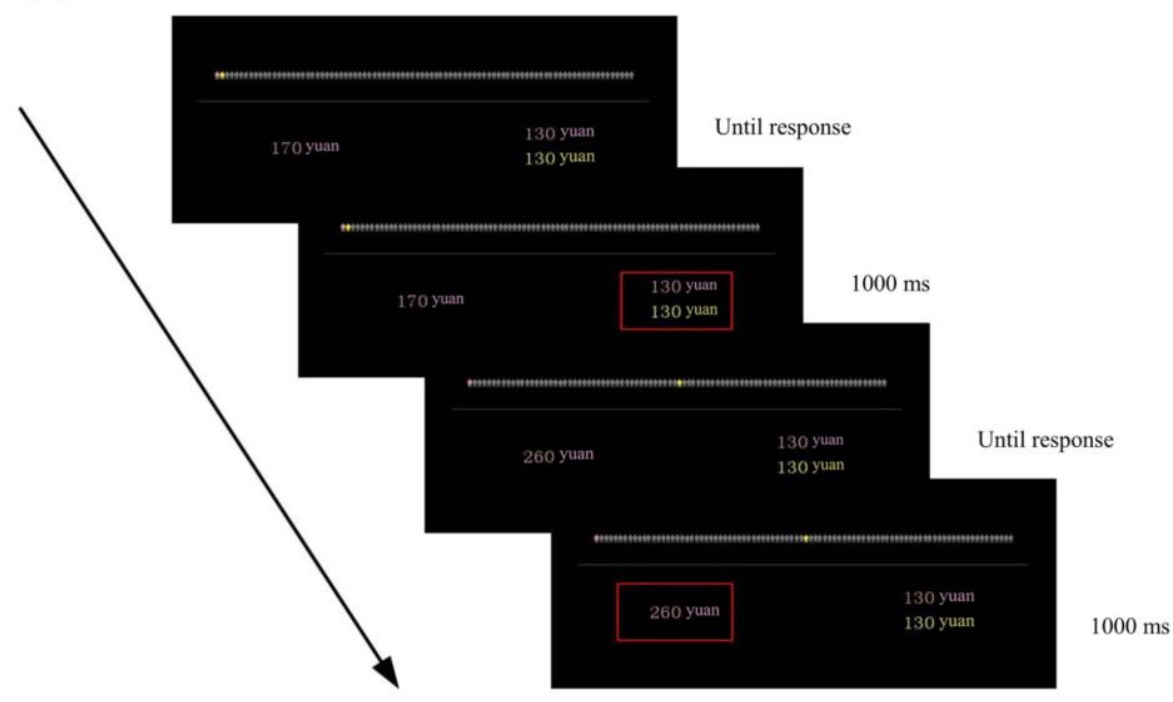


Fig 2. (a) Experimental schematic diagram. Three participants participated in the gamble task, one paired set of friends and a stranger. The paired friends' EEG was simultaneously recorded. Everyone was asked to observe the other person's card selection as well as the feedback outcomes regardless of whether it was their turn to play. (b) Experimental design sketch. First, the screen shows the subject's name to indicate whether it was their turn to play the gambling game. Then, the subjects played the gambling game for 24 consecutive trials. In each block, there was one round for each subject. The experiment lasted five blocks in total.

(a)

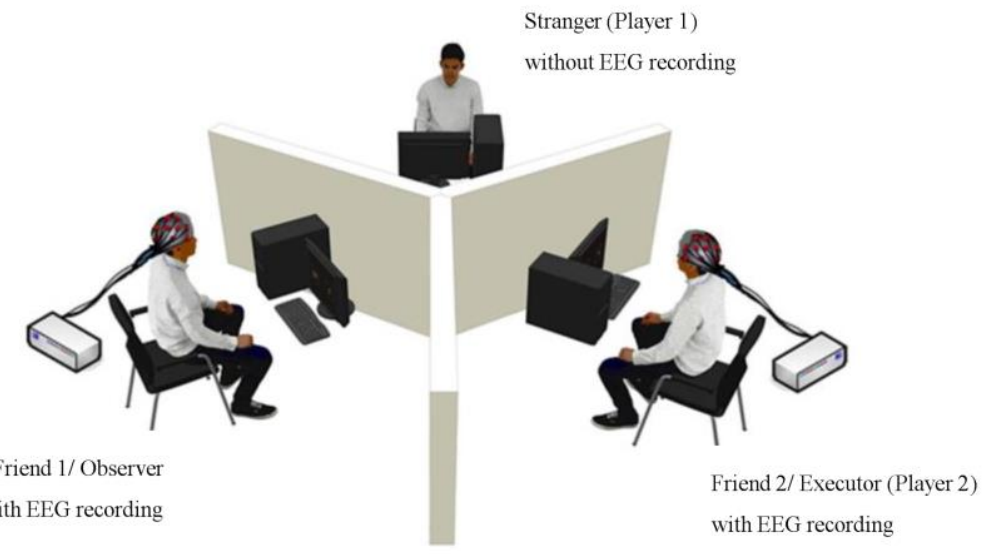

(b)

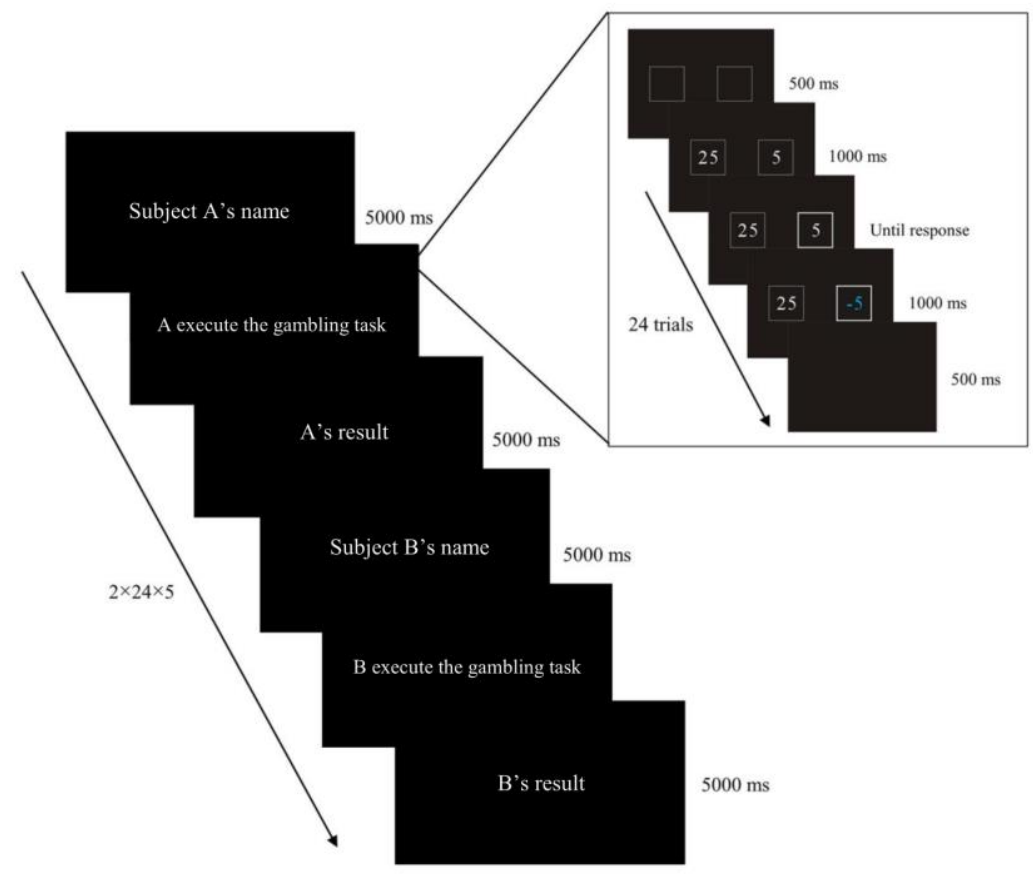


Fig 3. Fitting of the hyperbolic discount function for both groups.

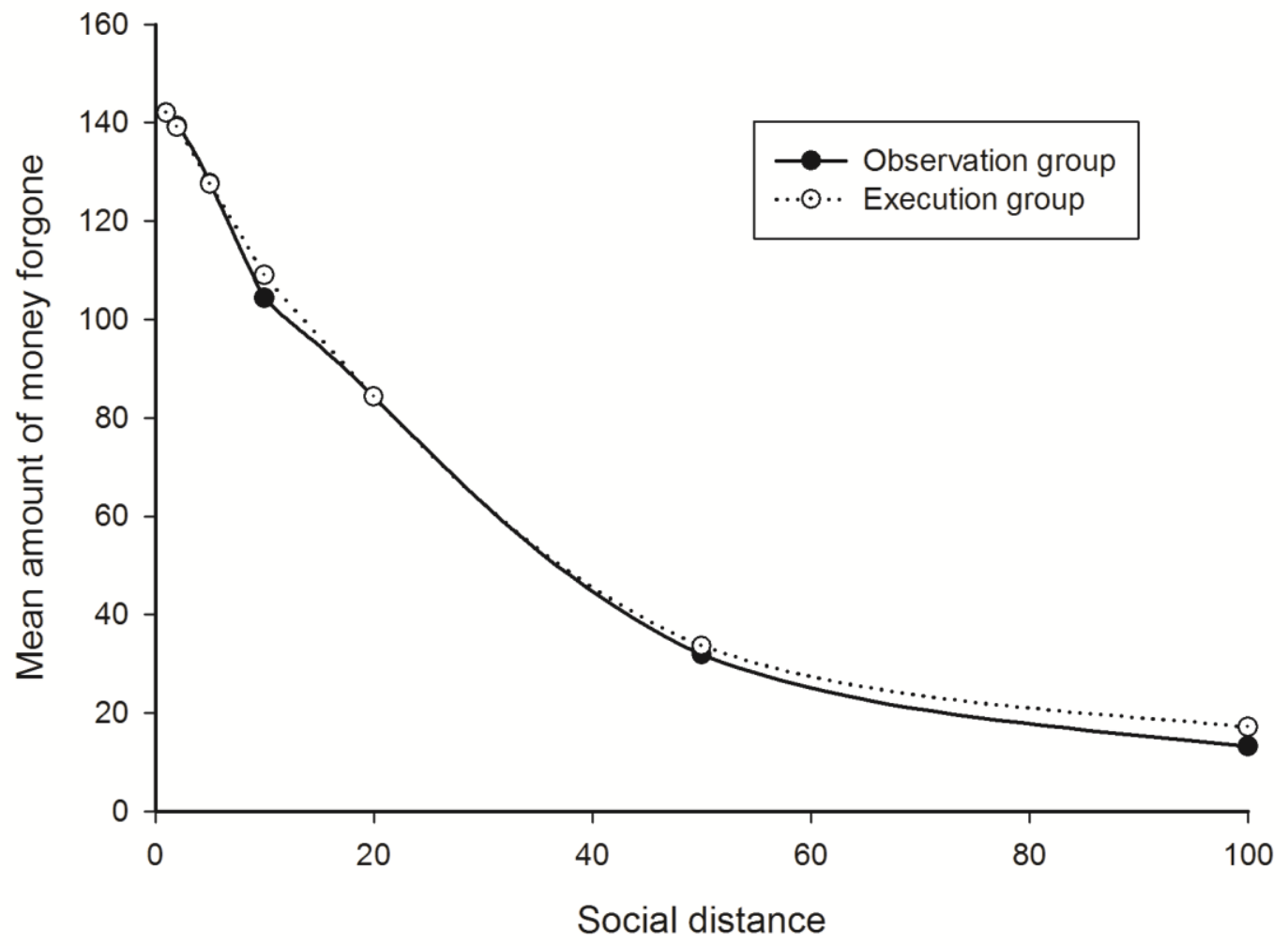


Fig 4. (a) FRN and d-FRN results for the observation group. Grand-average ERP waveforms from channels $\mathrm{Fz}, \mathrm{FCz}$, and $\mathrm{Cz}$ as a function of agency (friend vs. stranger) and valence (gain vs. loss) for feedback outcomes (left), as well as the FRN difference waveform (d-FRN) at these channels based on agency (right). (b) Topographic maps for the FRN and d-FRN in the observation group.
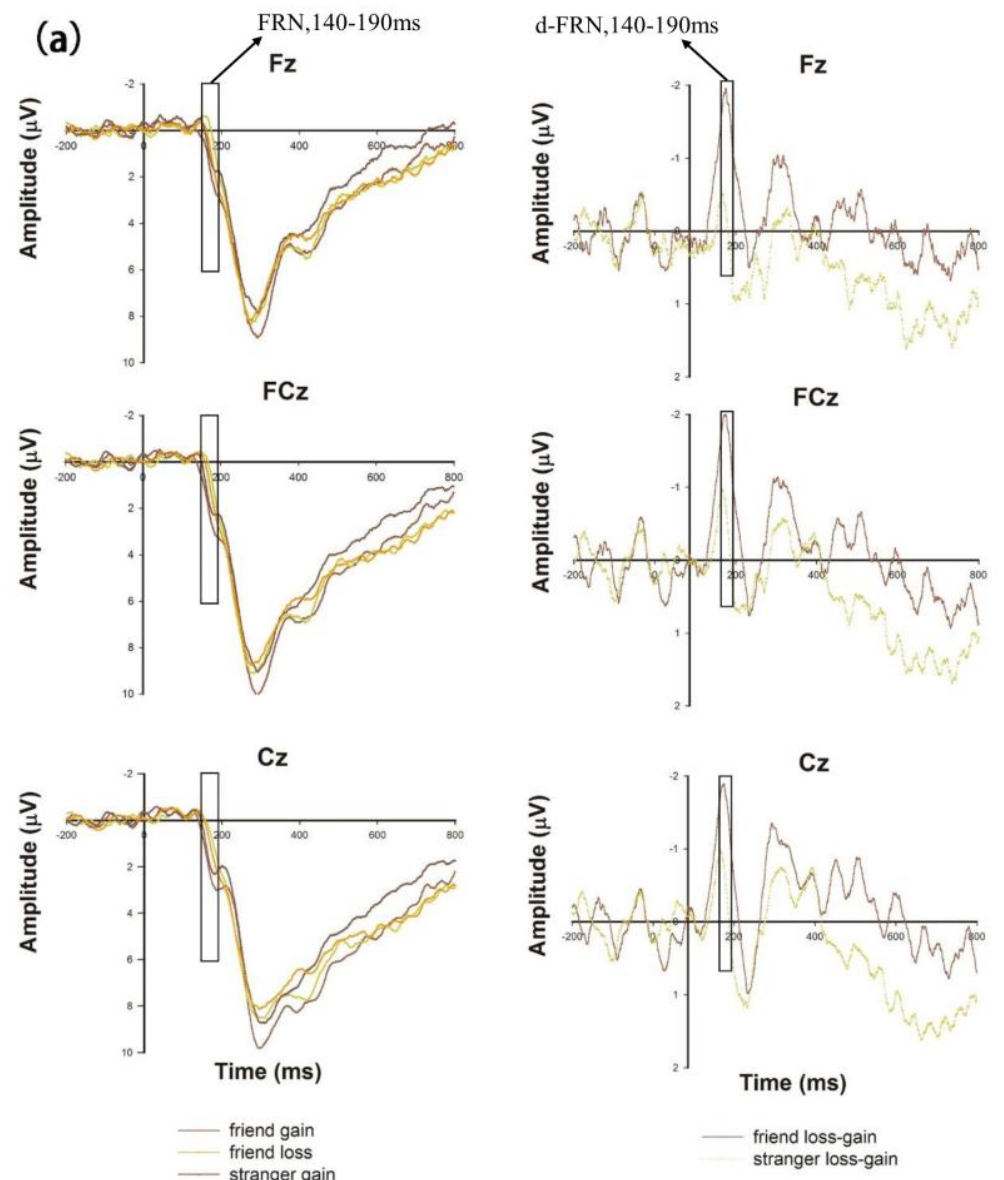

(b)
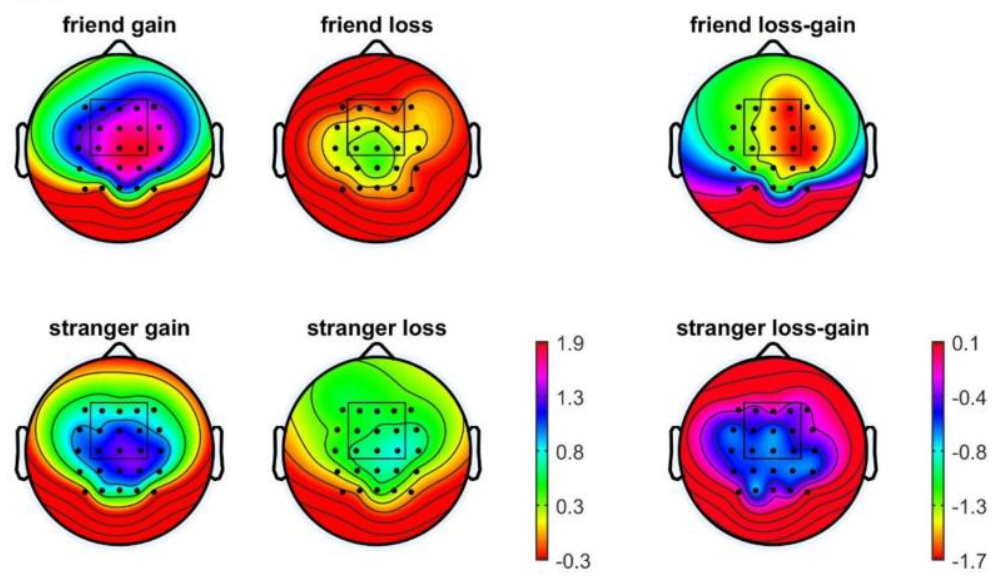
Fig 5. (a) P300 results for the observation group. Grand-average ERP waveforms from channels $\mathrm{Cz}, \mathrm{CPz}$, and $\mathrm{Pz}$ as a function of agency (friend vs. stranger) and valence (gain vs. loss) for feedback outcomes. (b) Topographic maps for the P300 in the observation group.

(a)

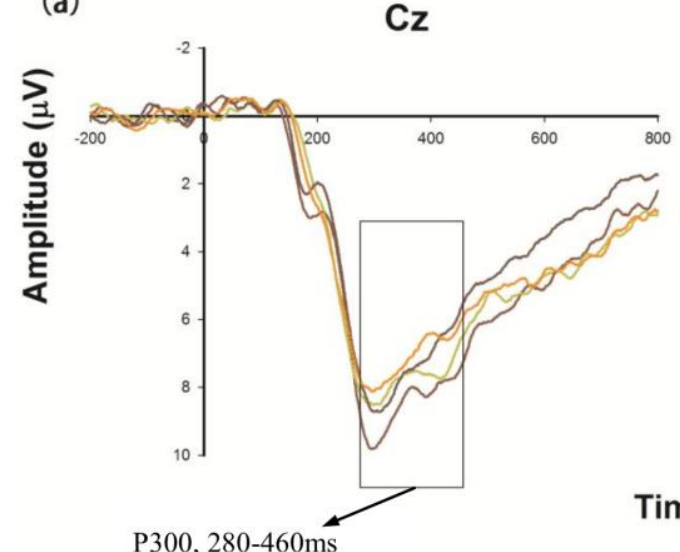

Pz

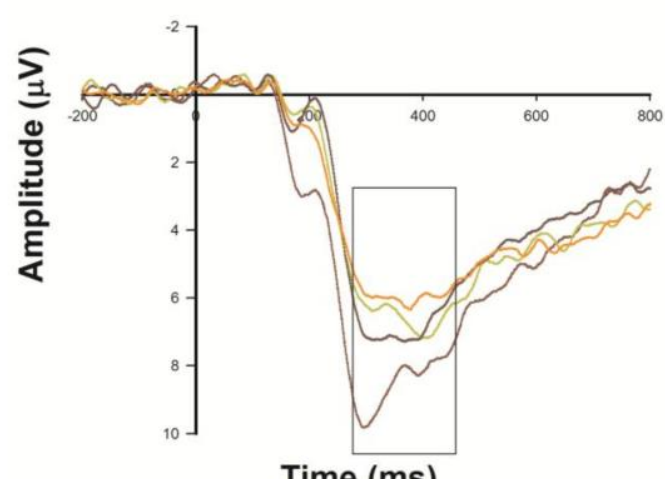

Time (ms)
Time (ms)

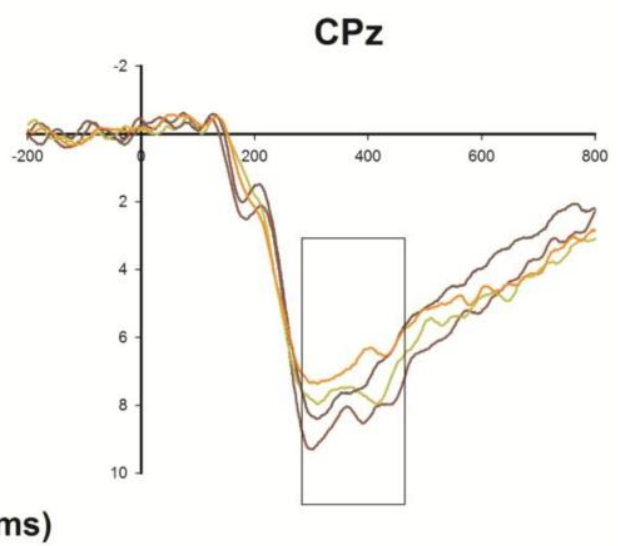

(b)
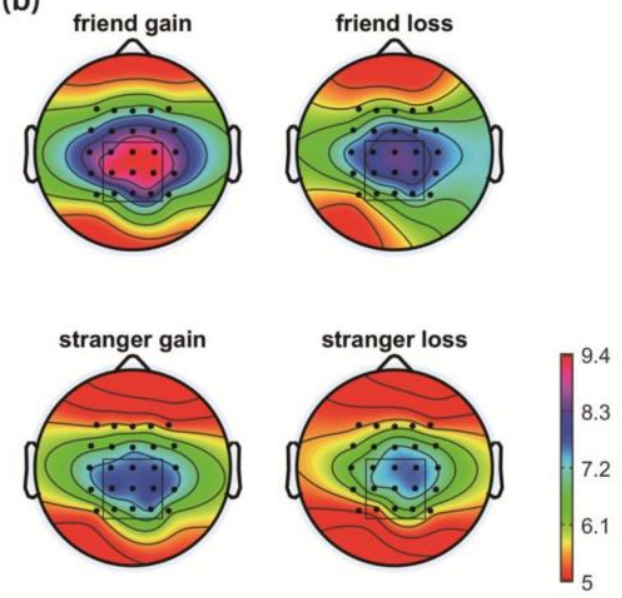
Fig 6. (a) FRN and d-FRN results for the execution group. Grand-average ERP waveforms from channels $\mathrm{Fz}, \mathrm{FCz}$, and $\mathrm{Cz}$ as a function of agency (self vs. stranger) and valence (gain vs. loss) for feedback outcomes (left), as well as the FRN difference waveform at these channels based on agency (right). (b) Topographic maps for the FRN and d-FRN in the execution group.
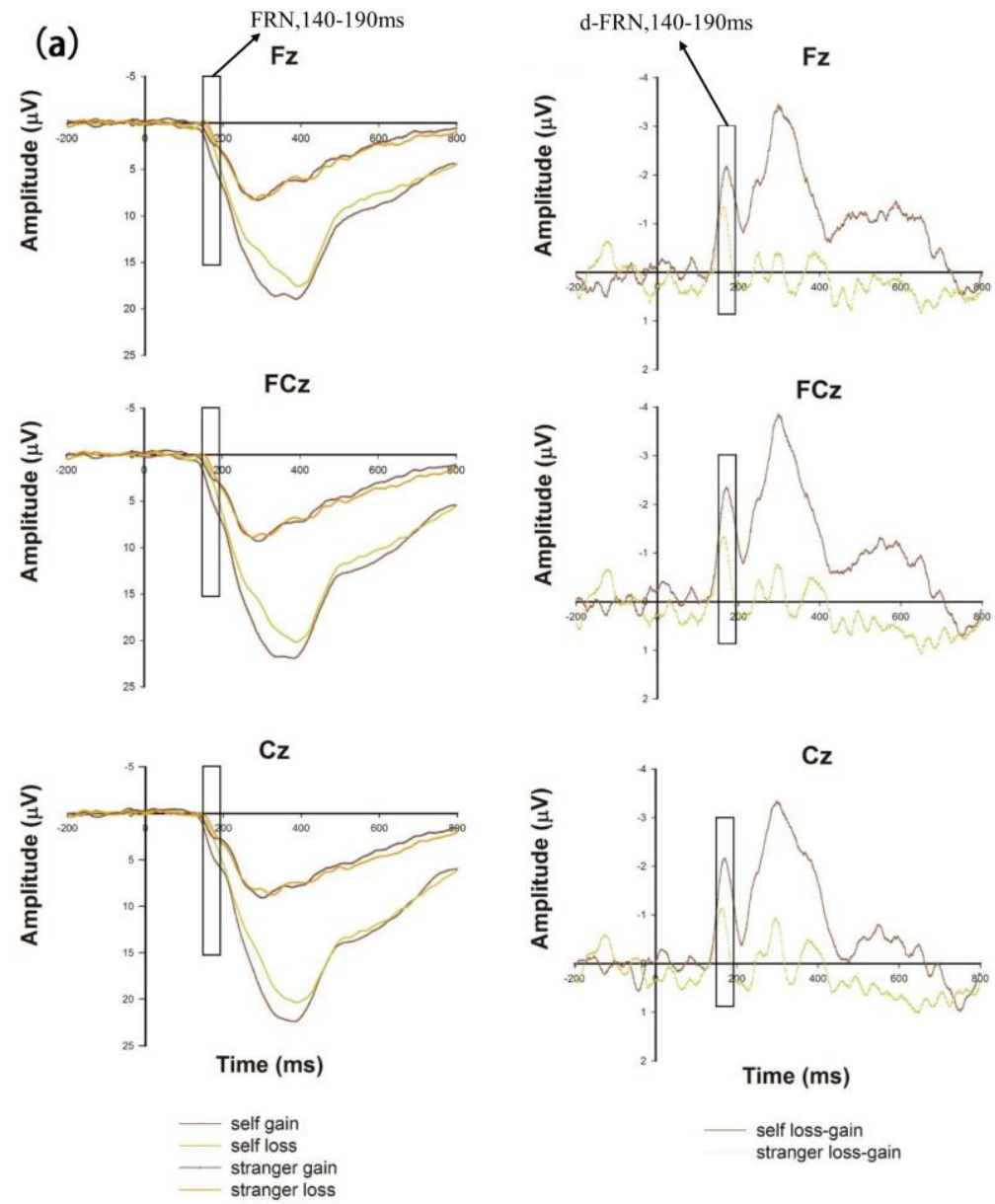

(b)
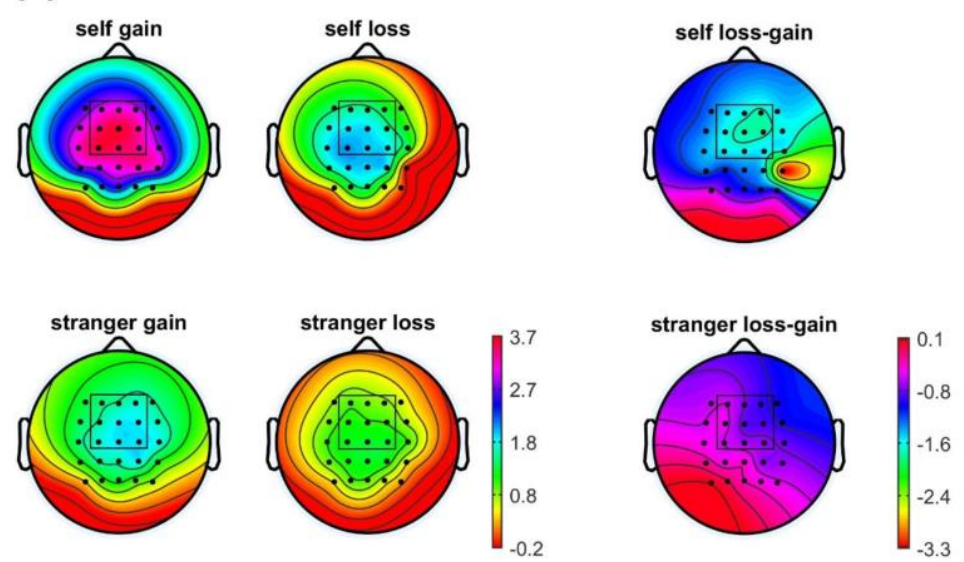
Fig 7. (a) P300 results for the execution group. Grand-average ERP waveforms from channels $\mathrm{Cz}, \mathrm{CPz}$, and $\mathrm{Pz}$ as a function of agency (self vs. stranger) and valence (gain vs. loss) for feedback outcomes. (b) Topographic maps for the P300 in the execution group.

(a)

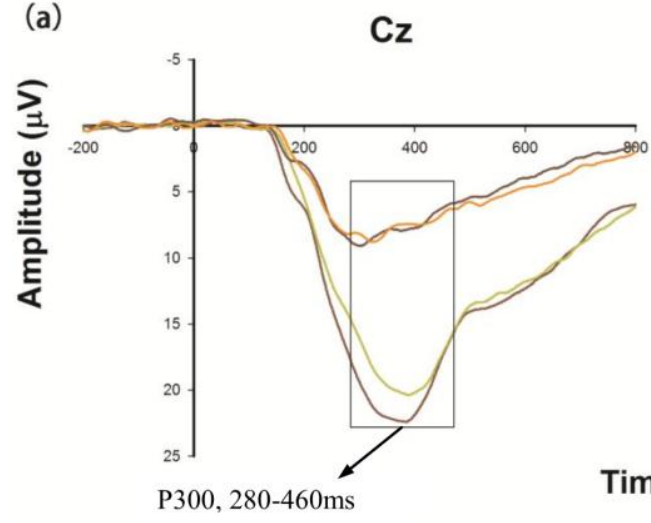

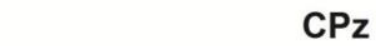

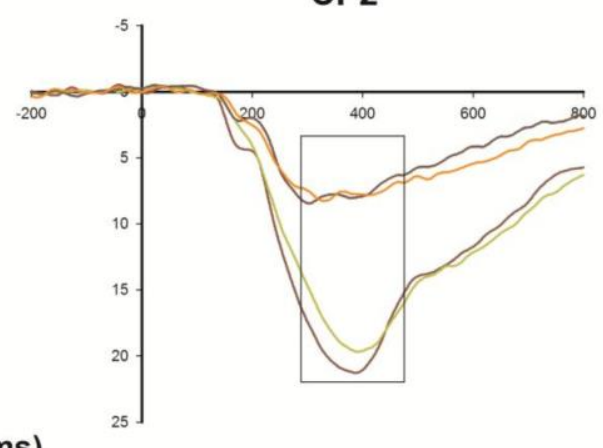

(b)

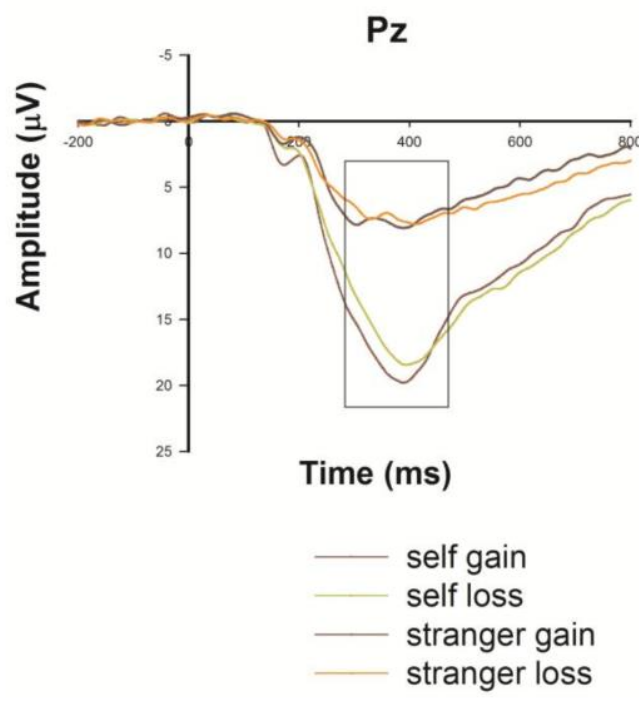

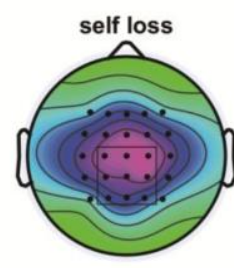
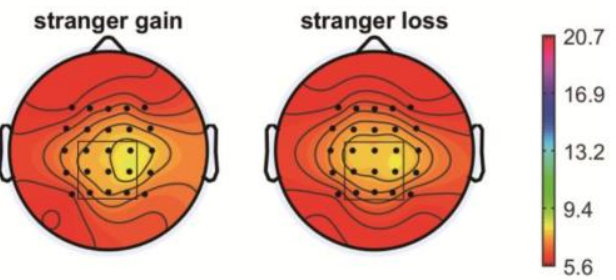
Fig 8. (a) Scatter plots of correlation results between $\ln (k)$ and d-dFRN amplitude in channel FCz as an example, which have a negative correlation. (b) Scatter plots of the correlation results between AUC and d-dFRN amplitude in channel FCz, which were positively correlated.
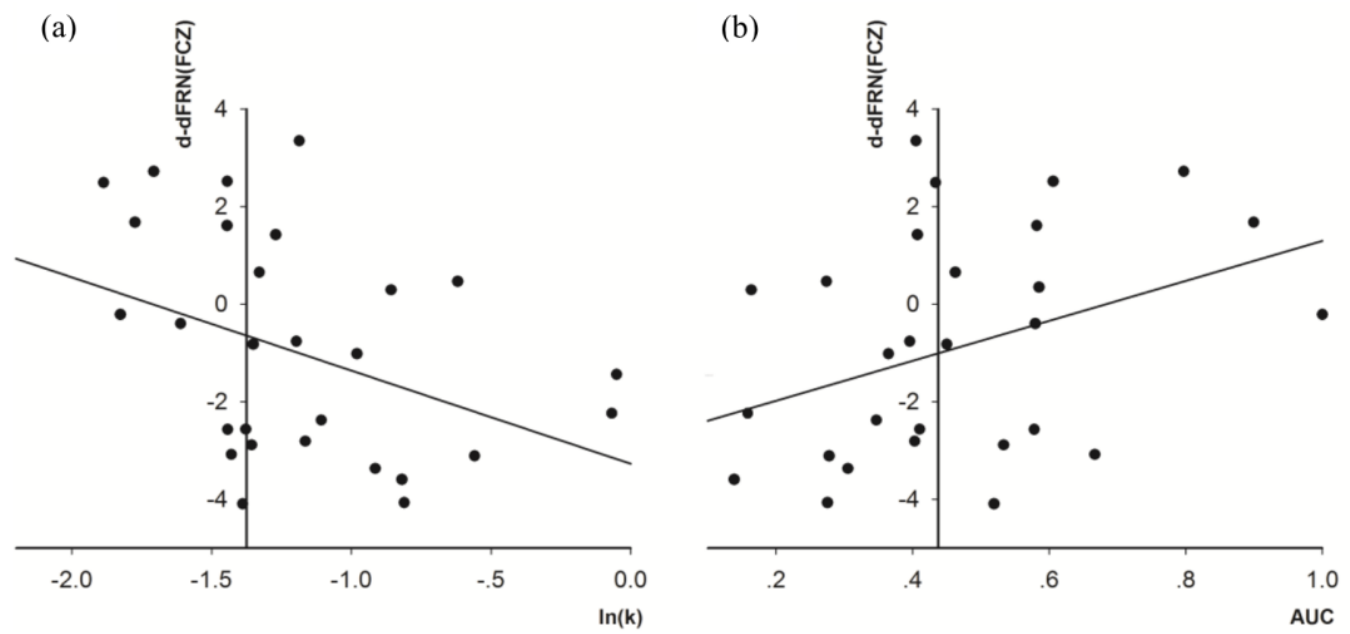